\title{
Technical validation of design of zero energy building in Ahvaz city based on reliability
}

\author{
Mohammad Amin Mousavi SADAT ${ }^{1}$, Hosein Mohammad Nezhad SHOURKAEI ${ }^{* 2}$, Sudabeh SOLEIMANI ${ }^{3}$ \\ 1 M.Sc. student of electrical power engineering, Department of electrical and computer engineering, Science and \\ research branch, Islamic Azad University, Tehran, Iran
}

2 Assistant Professor of Islamic Azad University, Department of electrical and computer engineering, Science and research branch, Islamic Azad University, Tehran, Iran

3 Associate Professor of Islamic Azad University, Department of electrical and computer engineering, Science and research branch, Islamic Azad University, Tehran, Iran

\begin{abstract}
High value of energy, limitation in primary resources of common energy and increasing energy consumption in building have enticed the researchers to use renewable energy sources and provide the required energy of building including lighting, heating and cooling and this trend was developed to provide all the required energy of building. Establishment of zero energy building in terms of type of materials, site and construction, height and type of heating and cooling systems based on climatic conditions is an unknown factor being evaluated in this paper. The best technical design was extracted using AutoCAD software and analytic software of Design builder. To select the size of system, System Advisor model (Sam) software was applied. The software model of solar cooling system was simulated using PISTACHE software. By technical evaluation by numerical and software method, the best technical design was selected in a building with commercial use with the total area of $1500 \mathrm{~m}^{2}$ and total land $460 \mathrm{~m}^{2}$ with 15 commercial units (two-story), the main steps were taken to achieve the purpose of study.
\end{abstract}

Keywords: Commercial building, Zero energy, Ahvaz, Photovoltaic.

\section{1- Introduction}

Shortage of fossil fuel and environmental pollutions has developed the discussions on environment and energy. Since the earl y 1970s, energy crisis, ozone layer depletion and global warming have led into the formulation of regulations to control energy consumption. Since then, sustainable design and development has been one of the important issues in zero energy buildings. The construction of these buildings has some unknown factors including materials, location angle, height and type of heating and cooling systems and these factors are examined in this technical evaluation. According to the data of energy balance in 2015, the highest energy consumption in Iran is dedicated to domestic and commercial, industry, transportation and agriculture sectors. Based on these statistics, energy consumption in domestic and commercial

\footnotetext{
*Corresponding author: Assistant professor of Islamic Azad University, Researches and sciences branch.
} 
sector is $55.4 \%$, industry $41.5 \%$, transportation $41 \%$ and agriculture $6.5 \%$. In other words, the majority of energy consumption share is dedicated to domestic and commercial sector but in developed countries, this sector has the lowest share compared to industry sector [1].

High value of energy, limitation in initial resources of common energy and increasing energy consumption in building have enticed the researchers to use renewable energy sources and provide the required energy of building including lighting, heating and cooling and this trend was developed to provide all the required energy of building. No fossil fuel is used in these buildings and they are called "zero energy building". Various studies have been conducted on design of zero energy houses and some of them are explained as: The study in [2] evaluates the simultaneous application of solar panels and energy storage batteries to supply domestic energy. Also, it is found whether simultaneous application of these two factors can supply required energy of electric cars or not. Also, network load, load displacement and reduction of energy are performed in the study of a zero energy building.

In [3], Thermal design of a modern, two floored, zero energy house in a desert compound with latitude 24.5 degree is examined. This study considers all equipment and air ventilation. Despite other designs, two-floor building of this study challenges the balance of produced and consumed energy.

In [4], the aim of this paper is to estimate the energy performance of a typical bioclimatic house equipped with a solar heating system located in the north Algeria (Algiers) and to investigate its conversion into a zero energy house by installing a grid connected PV system. To achieve this goal, a numerical model of the bioclimatic house coupled with the solar heating system is developed and validated with experimental data.

In [5], energy performance, financial feasibility and potential energy savings of zero energy houses were examined. Through the use of building computer simulation technique, a 5 stars energy rated house was modeled and validated by comparing the energy performance of a base case scenario to a typical house in Australia. By integrating energy reduction strategies and utilizing renewable energy such as solar energy, zero energy performance is achieved.

[6] Investigates cost-optimal solutions for the energy system design in a zero energy building and the subsequent grid impact. The authors use a Mixed Integer Linear (MILP) optimization model that simultaneously optimizes the building's energy system design and the hourly operation. The findings show that the energy system design and the grid impact greatly depend on the zero energy building definition, the existing policy instruments and on the current energy market conditions.

\section{2- The main design of building}

At first, zero energy building is designed using AutoCAD software and interior dimensions are designed using Design builder software. The optimal zero energy building design is presented based on the high energy on exterior surface. The building site is on the north of Ahvaz. One of the reasons to select this site is high income of residents in this region. Figure 1 shows the façade of zero energy building. The entire exterior surface of building and roof is covered with photovoltaic panels. Good insulation is used to avoid energy loss and also special materials are used in these buildings. The floor of building (area) is $436 \mathrm{~m} 2$, exterior surface area is $740 \mathrm{~m}^{2}$ and 
entire interior dimension is $1469 \mathrm{~m}^{3}$. This building is commercial with normal day's performance of 8 a.m to 5 p.m. and Thursdays until 2p.m and the building is closed on holidays. This building consists of two floors with 15 commercial units with different measurements. It has two WCs for men and women in each floor. The roof is smooth to install panel with definite angles. The building is constructed with 5degree angle to south east region [7].

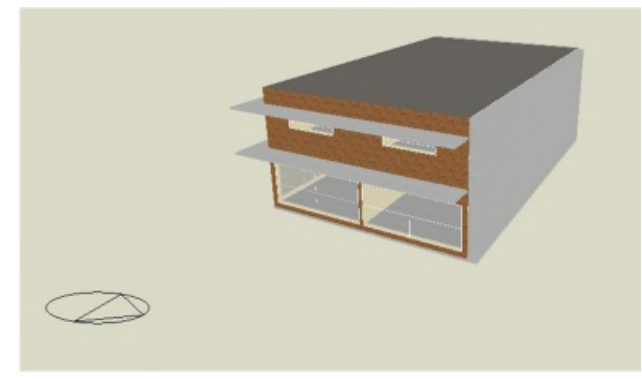

Figure 1: A 3D model of designed building

\section{3-Calculations of thermal and cooling loads of building}

We consider the building as a thermal grid and a flow grid and we write energy and air flow equations for different nodes and sites and by simultaneous solution of these equations, we determine the temperature of these sites and thermal transfer between both sites [8]. In thermal load calculations, hourly temperature is achieved as followings:

$T-\bar{T}=\frac{1}{2} A_{t} \cos \omega(t-15)$

Where $\mathrm{T}$ is hourly temperature, $\mathrm{t}$ time in hour and $\bar{T} \omega=\frac{2 \pi}{24} \cdot A_{t}, \bar{T}$ are obtained as:

$$
\begin{aligned}
& \bar{T}=\frac{1}{2}\left(T_{X}+T_{n}\right) \\
& A_{t}=\left(T_{X}-T_{n}\right)
\end{aligned}
$$

In these equations, $T_{X}$ indicates monthly average maximum temperature and $T_{n}$ monthly average minimum temperature. It is assumed that maximum daily temperature is occurred at $3 \mathrm{PM}$ and minimum temperature at $3 \mathrm{AM}$. The maximum daily temperature is PM (solar) and minimum temperature is one hour before sunshine [9].

\section{4-Calculations of radiation on flat surface}

To determine solar radiation intensity on different surfaces, the followings are used:

$$
I_{n}=K_{T} I_{o h}
$$


Bulletin de la Société Royale des Sciences de Liège, Vol. 86, special edition, 2017, p. 372 - 387

$$
\begin{aligned}
& I_{d h}=I_{h}-I_{b h} \\
& I_{o h}=I_{s c}\left[1+0.0033 \cos \left(\frac{360 N}{365}\right)\right] \cos \left(\theta_{z}\right) \\
& K_{T}=[\alpha+b \cos \omega(t-12)] \bar{K}_{T} \\
& \alpha=0.409+0.5061 \sin \left(\omega_{s}-60\right) \\
& b=0.6607-0.4767 \sin \left(\omega_{s}-60\right) \\
& \left\{\begin{array}{l}
I d h / I_{h}=1-0.249 K_{T} \quad, K_{T}<0.35 \\
I d h / I_{h}=1.557-1.84 K_{T}, 0.35<K_{T}<0.75 \\
I d h / I_{h}=0.177 \quad, K_{T}>0.75
\end{array}\right.
\end{aligned}
$$

In these equations, $\bar{T} \omega$ is monthly air clearness index (for clear and sunny days 0.7 , for cloudy days 0.2 ), KT is hourly clearness index, $I_{h}$ solar radiation on horizontal plane in $M J / \mathrm{m}^{2}, I_{d h}$ and $I_{b h}$ are diffuse and direct radiation, respectively on horizontal plane in $M J / \mathrm{m}^{2}, I_{o h}$ sun radiation intensity on a

Extraterrestrial horizontal plane in $M J / \mathrm{m}^{2}, I_{s c}$ is solar constant (equal to $1353 \mathrm{w} / \mathrm{m}^{2}$ ), $\mathrm{N}$ is day year ( $\mathrm{N}=1$ for the secondary initial day or $N=n+81$ and $\mathrm{n}$ indicates the day in Hijri year (lunar) and $n=1$ for the $1^{\text {st }}$ of Farvardin), $\theta_{z}$ is zenith angle and $\omega_{S}$ sunset angle. To determine $\theta_{z}, \omega_{S}$ the following equations are used:

$$
\begin{aligned}
& \cos \theta_{z}=\cos \delta \cos \phi \cos \omega+\sin \delta \sin \phi \\
& \cos \omega_{S}=-\tan \phi \tan \delta
\end{aligned}
$$

Where, $\phi$ is latitude in Ahvaz city $(\phi=32.5), \delta$ is declination angle and $\omega$ is hourly angle equal to 15 degree per hour (it is negative in the morning and it is positive in the afternoon). $\delta$ angle is achieved by the following equation:

$$
\delta=23.45 \sin \left(360 \frac{284+N}{365}\right)
$$


To determine solar radiation intensity on walls, the following equation is used [9]:

$$
I_{j}=R_{b j} I_{b h}+\frac{1}{2} I_{d h}+\frac{1}{2} \rho_{g r} I_{h}
$$

$\mathrm{J}$ indicates the wall direction (eastern, southern, western and northern), indices b,d show direct and diffuse radiation, respectively and $\mathrm{h}$ indicates radiation on horizontal plane, $\rho_{g r}$ indicates ground reflection index and it is ranging 0.2 to 0.5 based on the coverage of the ground around the wall. In this equation, $R_{b j}$ indicates direct radiation on wall to direct radiation on horizontal plane and is determined using the following Equation.

$$
R_{b j}=\frac{\cos \theta}{\cos \theta_{z}}
$$

In this equation, $\theta$ angle is achieved of the total equation and it is $\beta=90^{\circ}$ for vertical walls and $\gamma=0$ for southern wall. This angle is true in the following equation [9]:

$$
\begin{aligned}
& \cos \theta=\sin \delta \sin \phi \cos \beta-\sin \delta \cos \phi \sin \beta \cos \gamma \\
& +\cos \delta \cos \phi \cos \beta \cos \omega+\cos \delta \sin \phi \sin \beta \cos \gamma \cos \\
& +\cos \delta \sin \beta \sin \gamma \sin \omega
\end{aligned}
$$

\section{5-Calculation of radiation on sloped surface}

To calculate energy receiving in surface of collection (photovoltaic plane or solar collector) at nth day from the first of Jan at altitude $\phi, \beta$ angle to horizontal plane, to the south, the following procedure is used [10]:

At first, daily average radiation in month $(\mathrm{H})$ is determined. These values are measured and computed for different cities in all months of year. In the first step, Extraterrestrial sun radiation $(\bar{H} 0)$ is calculated of the following equation:

$$
\begin{aligned}
& \bar{H} 0=\frac{24 \times 3600 \times G_{S C}}{\pi}\left(1+0.033 \cos \frac{360 n}{365}\right) \\
& \times\left(\cos \phi \cos \delta \sin \omega_{S}+\frac{\pi}{180} \omega_{S} \sin \phi \sin \delta\right)
\end{aligned}
$$

Where $G_{s c}$ is solar constant $1372 \mathrm{w} / \mathrm{m}^{2} . \delta$ denotes solar declination and solar hour at sunrise and $\omega_{S}$ denotes sunrise as obtained, respectively:

$$
\delta=23.45 \sin \left(360 \frac{284+n}{365}\right)
$$


Bulletin de la Société Royale des Sciences de Liège, Vol. 86, special edition, 2017, p. 372 - 387

$$
\omega_{s}=\arccos (-\tan \phi \tan \delta)
$$

In the second step, after calculation of Extraterrestrial sun radiation by $\bar{K} t=\bar{H} / \bar{H}_{0}$, lighting index of each month is calculated. Based on the calculated value, diffused radiation to total radiation is achieved of the following equation:

$$
\frac{\bar{H} d}{\bar{H}}=\left\{\begin{array}{l}
1.39-3.56 K_{t}+4.189 K_{T}^{2}-2.13 K_{T}^{3} \omega_{s} \leq 81.4 \\
1.39-3.022 K_{t}+3.427 K_{T}^{2}-1.821 K_{T}^{3} \omega_{s}>81.4
\end{array}\right.
$$

It is possible that based on the slope angle of collector, after sunrise, the radiation doesn't reach the collector surface; it is required to calculate $\omega_{S}^{\prime}$ by the following equation:

$$
R_{b}=\frac{\cos (\phi-\beta) \cos \delta \sin \omega_{S}^{\prime}+\frac{\pi}{180} \omega_{s}^{\prime} \sin (\phi-\beta) \sin \delta}{\cos \phi \cos \delta \sin \omega_{S}+\frac{\pi}{180} \omega_{S} \sin \phi \sin \delta}
$$

The solar energy received on a solar collector is the sum of direct radiation, diffused and reflected radiation of the ground. To consider diffuse and reflected radiation, besides the direct solar radiation on collector surface, the total radiation on sloped surface to horizontal surface (R) should be calculated by the following formula:

$$
R=\left(1-\frac{\bar{H} d}{\bar{H}}\right) R_{b}+\frac{\bar{H} d}{\bar{H}}\left(\frac{1+\cos \beta}{2}\right)+\rho\left(\frac{1-\cos \beta}{2}\right)
$$

In the final stage, total radiation on sloped surface $\left(\bar{H}_{t}\right)$ is achieved of the following equation [11]:

$$
\bar{H}_{t}=R \times \bar{H}
$$

\section{6-The selection of exterior design of building}

As it was said, the architecture of these buildings is of great importance as a good design is the one covering both approaches and reduces the building energy and store clean energy in the building with a pretty façade to attract the attention of buyers. The calculation of thermal loss of building is the best method to achieve the best façade of existing ideas. The surface thermal loss is as:

$$
Q=U A\left(T_{\text {in }}-T_{\text {out }}\right)
$$

In this equation, $Q$ is transferred heat in w, An area in $\left(m^{2}\right)$, $\mathrm{U}$ general index of heat transfer in $\left(\mathrm{W} / \mathrm{m}^{2} .{ }^{\circ} \mathrm{C}\right), T_{\text {in }}$ is inside design temperature in $\left({ }^{\circ} \mathrm{C}\right)$ and $T_{\text {out }}$ is outside design in $\left({ }^{\circ} \mathrm{C}\right)$. 
Thermal loss via the air in the building is not suitable in heating and cooling system. The thermal loss of air penetration inside the building is calculated as:

$$
Q=m c\left(T_{\text {in }}-T_{\text {out }}\right)
$$

In this equation, $\mathrm{m}$ is the mass of inside air in hour and $\mathrm{c}$ is specific thermal coefficient of air in (kcal $\left./ \mathrm{kg} .{ }^{\circ} \mathrm{C}\right)$.

\section{7- The features of studied building}

The plan is designed for a commercial building. A summary of its features is shown in Table 1 .

Table 1- The separated features of building

\begin{tabular}{|c|c|c|}
\hline Building information & Value & Unit \\
\hline Area of controlled space & 436 & $\mathrm{~m}^{2}$ \\
\hline Building volume & 1469 & $\mathrm{~m}^{3}$ \\
\hline Exterior shell area & 740 & $\mathrm{~m}^{2}$ \\
\hline $\begin{array}{c}\text { The average weight thermal } \\
\text { transfer of shell }\end{array}$ & 0.336 & $W / \mathrm{m}^{2} \cdot{ }^{\circ} \mathrm{C}$ \\
\hline
\end{tabular}

A good shade is used for southern windows in summer to reduce cold air. Figure 2 shows the sun location in two days July 15 (summer) and at 15:00.

Table 2 illustrates the existing spaces in the building.

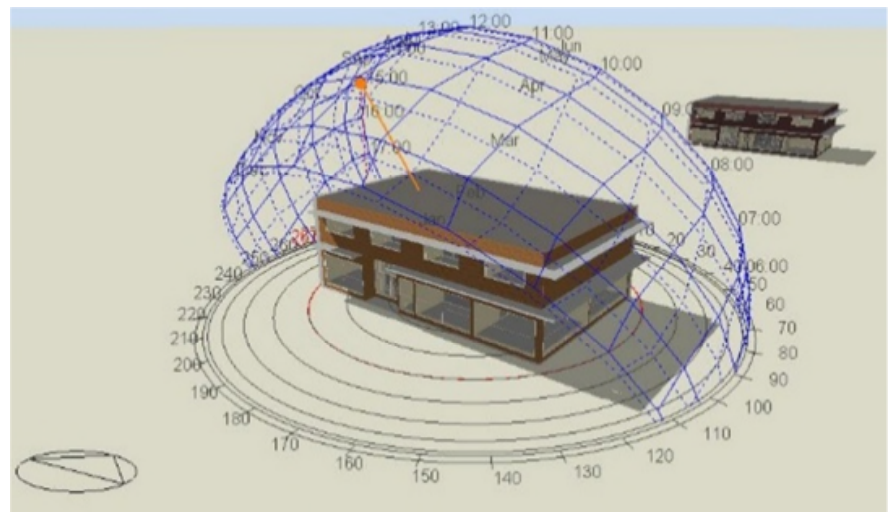

Figure 2- The sun location in a summer noon

Table 2- The measurement of inside of building

\begin{tabular}{|c|c|c|c|}
\hline Space & Measurement $\left(\mathrm{m}^{2}\right)$ & Space & Measurement $\left(\mathrm{m}^{2}\right)$ \\
\hline Store -01 & 20.45 & Store - 12 & 28.3 \\
\hline Store - 02 & 14.2 & Store - 13 & 13.65 \\
\hline Store - 03 & 29.5 & Store - 14 & 13.65 \\
\hline
\end{tabular}


Bulletin de la Société Royale des Sciences de Liège, Vol. 86, special edition, 2017, p. 372 - 387

\begin{tabular}{|c|c|c|c|}
\hline Store - 04 & 29.5 & Store - 15 & 12 \\
\hline Store - 05 & 13.65 & Ground floor hall & 69.75 \\
\hline Store - 06 & 13.65 & First floor hall & 66.65 \\
\hline Store - 07 & 12 & WC of ground floor & 19.35 \\
\hline Store - 08 & 19.35 & WC of first floor & 19.35 \\
\hline Store - 09 & 13.65 & Information & 4 \\
\hline Store - 10 & 13.65 & Entrance & 8.85 \\
\hline Store - 11 & 28.835 & Total & 463.45 \\
\hline
\end{tabular}

Regarding lighting, we should consider that the majority of spaces in architecture are designed to use natural light. Using more windows with high thermal features on the south of building and their correct design, 15 degree rotation of building to the west and other items are some solutions for maximum use of natural lighting. By considering demand factor, the sum of power of lighting system and other equipment in $\mathrm{W}$ is shown in Table 3.

The calculations of heating and cooling loads are important in the design of a zero energy building as the design of all renewable energy production systems including solar heating is dependent upon it. The new energy systems are implemented in buildings with suitable thermal features (economic justification). We assume that insulation of shell of building, change of doors and windows and sealing are performed and thermal characteristics are optimal. Also, the entire electrical equipment including computer and lighting systems are the most optimal. The structure in the shell of building has average weight and the features of walls are shown in Table 4.

Table 3-Lighting and equipment of building features

\begin{tabular}{|c|c|c|c|}
\hline Space & Total power $(\mathrm{W})$ & Space & Total power $(\mathrm{W})$ \\
\hline Store - 01 & 272 & Store - 12 & 309.5 \\
\hline Store - 02 & 227 & Store - 13 & 309.5 \\
\hline Store - 03 & 309.5 & Store - 14 & 227 \\
\hline Store - 04 & 309.5 & Store - 15 & 227 \\
\hline Store - 05 & 227 & Ground floor hall & 214.5 \\
\hline Store - 06 & 234.5 & First floor hall & 347 \\
\hline Store - 07 & 214.5 & WC of ground floor & 347 \\
\hline Store - 08 & 272 & WC of first floor & 248 \\
\hline Store - 09 & 234.5 & Information & 248 \\
\hline Store - 10 & 227 & Entrance & 210 \\
\hline Store - 11 & 37.5 & Total & 5272.5 \\
\hline
\end{tabular}

Table 4- The measurement of interior spaces of building

\begin{tabular}{|c|c|c|}
\hline Space & Thickness $(\mathrm{m})$ & Thermal conductivity coefficient $\left(\mathrm{W} / \mathrm{m}^{2} .{ }^{\circ} \mathrm{C}\right)$ \\
\hline Brick façade (light) & 0.105 & 0.84 \\
\hline Cement sand mortar & 0.02 & 1.15 \\
\hline Extruded polystyrene & 0.15 & 0.034 \\
\hline Concrete & 0.1 & 0.51 \\
\hline Gypsum and soil & 0.025 & 0.4 \\
\hline Gypsum and paint & 0.01 & 0.2 \\
\hline
\end{tabular}


Based on the values, surface thermal transfer coefficient is 0.203 and surface thermal transfer coefficient for the ceiling is 0.24 . In case of not using insulation, the thermal transfer coefficient of wall is 1.5 and the thermal transfer coefficient of ceiling is 2.13 .

\section{8-Determine bias point of temperature in summer and winter}

To determine set point to provide the comfort, ISO7730 standard is used. Predicted Mean Vote Index ( PMV ) is an important factor to compute comfort. By determining PMV, Predicted Percentage Dissatisfied Index (PPD) is calculated. To determine set point in this study, we consider a logical level of dissatisfaction (PPD) and calculate PMV and then we determine suitable temperature. The relationship between PPD, PMV is shown in Figure 3. Our aim is maximum $10 \%$ of dissatisfaction of employees.

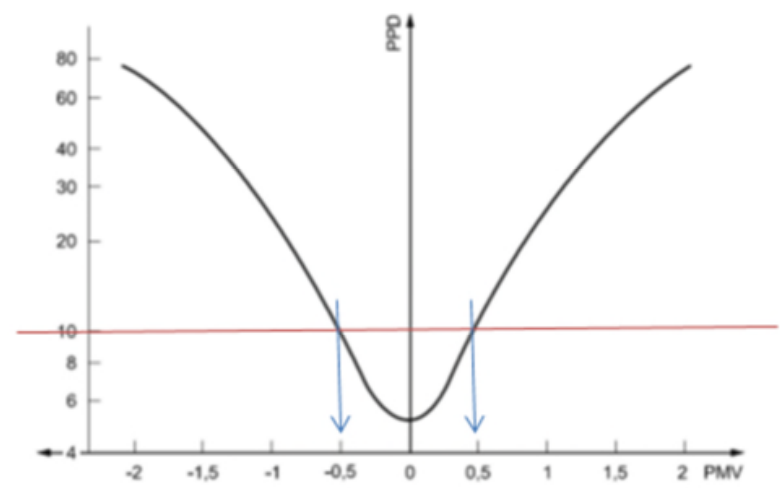

Figure 3- The relationship between PPD, PMV

As shown, by considering $10 \%$ dissatisfaction, we are in standard range. Based on weather data of Ahvaz city and commercial use of building, $18,26^{\circ} \mathrm{C}$ are at maximum comfort range. Finally, for set point of winter, temperature $25^{\circ} \mathrm{C}$ and for summer $20^{\circ} \mathrm{C}$ is considered.

\section{9-Air change (ACH)}

A part of cooling and heating loads of air penetration are due to lack of sealing of windows and doors, around the sockets, input and output air valves and they should be eliminated. The optimal structure in the building and using high efficiency glasses reduce $\mathrm{ACH}$. But based on the commercial use of opening and closing the main door, $\mathrm{ACH}$ is considered as 0.8 . In case of not opening and closing based on the building shell, this value is optimized and reduced to 0.1 .

\section{0-Calculation of design load and consumption simulation}

The thermal loads of each of spaces are computed by Energy Plus and Design Builder software and we present the results of software simulation of buildings.

To calculate cooling load, Design builder software is used. The cooling and heating load are $46.6 \mathrm{~kW}$ and $20.65 \mathrm{~kW}$, respectively (for a building with non-optimal shell, these values are $81.46 \mathrm{~kW}$ and $33.5 \mathrm{~kW}$, respectively). To supply $40 \%$ of cooling loads, absorptive chiller with solar vacuum tube collector is used. It is worth to mention that the computed heating and cooling 
load is the requirement of the building to supply heating and cooling and is different from annual and monthly energy consumption. Figures 4,5 show the details of these loads.

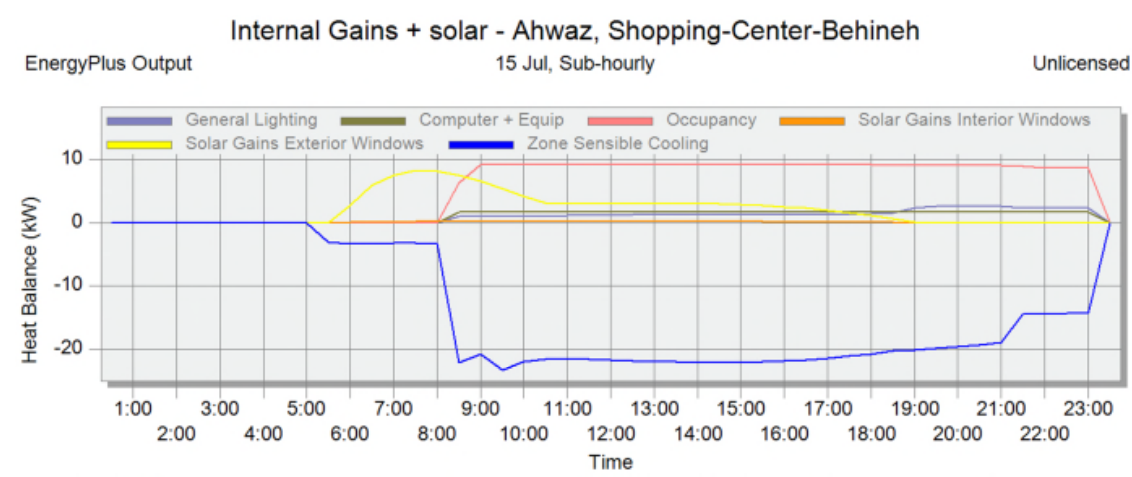

Figure 4- Different parts of cooling load of building (thermal balance)

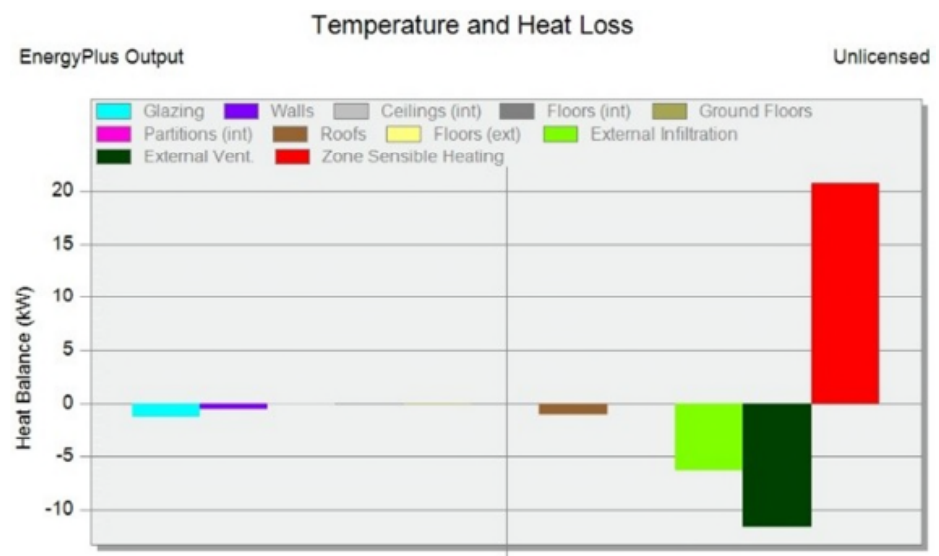

Figure 5- Different parts of heating load of building (thermal balance)

As shown, the majority of cooling load is dedicated to sun and the majority of heating load is dedicated to ventilation.

The energy consumptions as cooling, heating, hot water, lighting and equipment as hourly, daily and monthly are simulated. Table 5 shows the cooling load values (without considering their production system efficiency), lighting and equipment. To achieve zero energy building, it is required to supply these utilities. Based on hot climate of Ahvaz, the type of use (high production of heat by equipment and people and no efficiency at night) and optimal shell of building (the heat of people and equipment is maintained via a good insulator and thermal mass inside the space) and there is no considerable need to high temperature water.

Regarding cooling index, the efficiency of cooling equipment is not entered. For example, if COP of cooling system is considered as 4.5 , the cooling electricity index is $38.5 \mathrm{kWh} / \mathrm{m} 2$. Based on the climate of Ahvaz city, the shell with high thermal resistance and building use, the need to cool air in winter is computed and this is ignored. Figures 6-11 show the results of simulation in hourly, daily regarding site data, data of air penetration, ventilation, fuels, thermal comfort, carbon dioxide production and system loads.

Table 4- The monthly loads of cooling, lighting and equipment in building 
Bulletin de la Société Royale des Sciences de Liège, Vol. 86, special edition, 2017, p. 372 - 387

\begin{tabular}{|c|c|c|c|}
\hline Month & Lighting (KW) & Electrical equipment (KW) & Cooling load (KW) \\
\hline Jan & 300 & 364 & --- \\
\hline Feb & 345 & 340 & --- \\
\hline March & 365 & 376 & 3252 \\
\hline April & 336 & 340 & 5713 \\
\hline May & 367 & 376 & 9714 \\
\hline June & 335 & 364 & 11221 \\
\hline July & 352 & 376 & 13435 \\
\hline August & 264 & 376 & 13688 \\
\hline Sep & 256 & 364 & 10526 \\
\hline Oct & 395 & 376 & 8919 \\
\hline NOV & 386 & 364 & 3920 \\
\hline DEC & 380 & 352 & --- \\
\hline Total & 4372 & 4365 & 80388 \\
\hline
\end{tabular}

In this study, the total energy of zero energy building including electricity of cooling systems, electricity consumption of solar systems, consumption of utilities of building, lighting, fans and pumps are $31141 \mathrm{kw} / \mathrm{h}$ and electricity generation of this building is $32017 \mathrm{kw} / \mathrm{h}$.

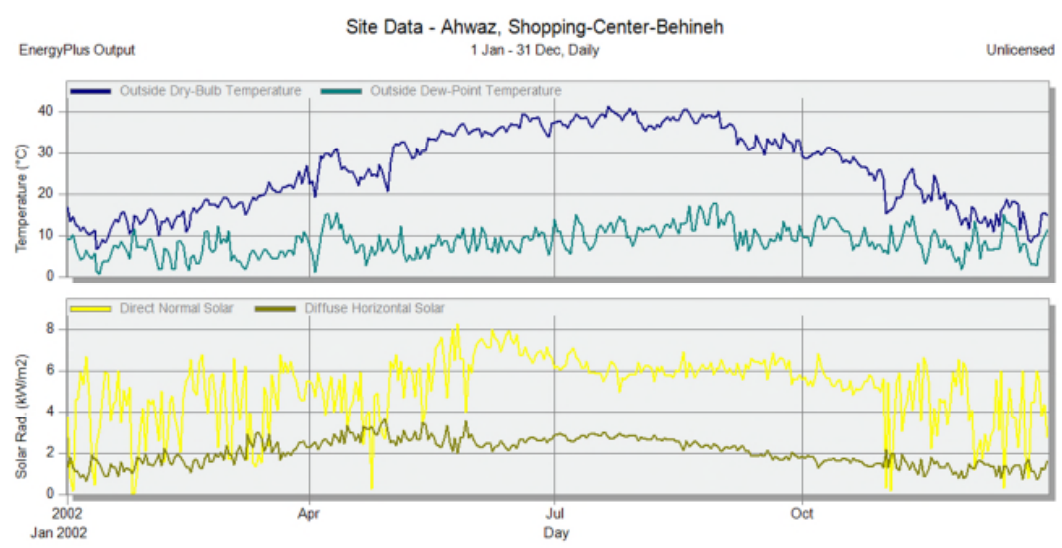

Figure 6-The daily data of site (dry temperature, dew point and solar radiation)

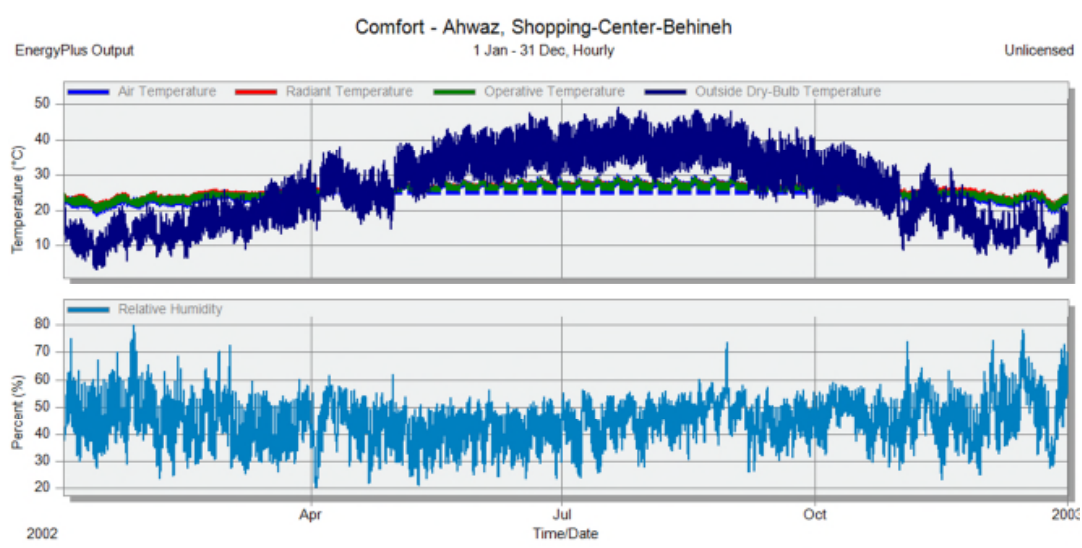

Figure 7-The hourly results of thermal comfort parameters in the building (temperature and relative humidity) 
Bulletin de la Société Royale des Sciences de Liège, Vol. 86, special edition, 2017, p. 372 - 387

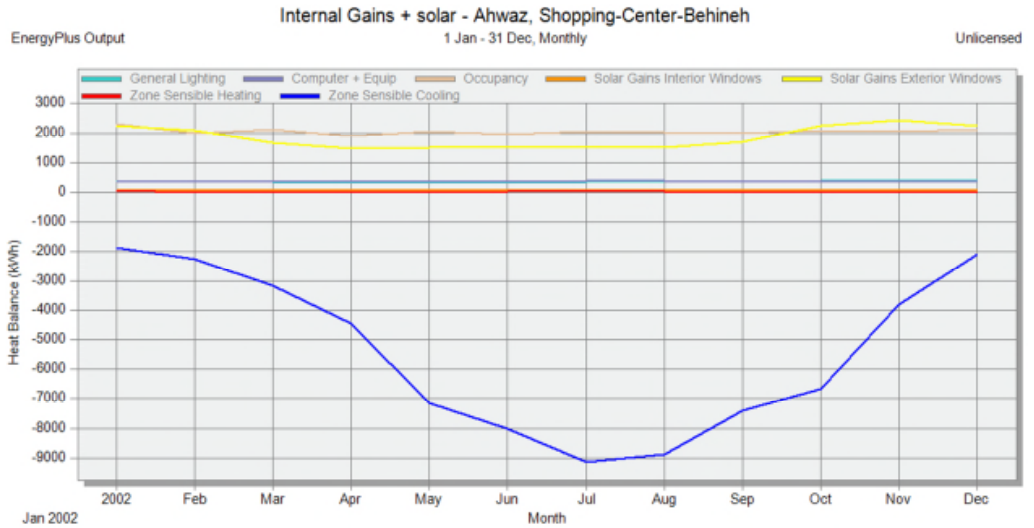

Figure 8- Monthly results of gained loads and solar loads

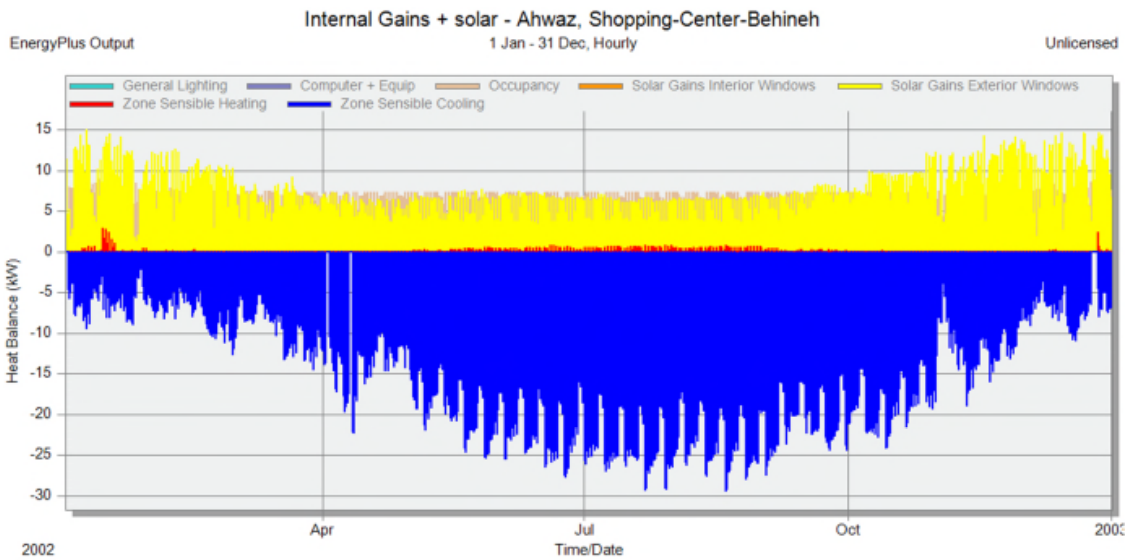

Figure 9- The hourly results of gained and solar loads

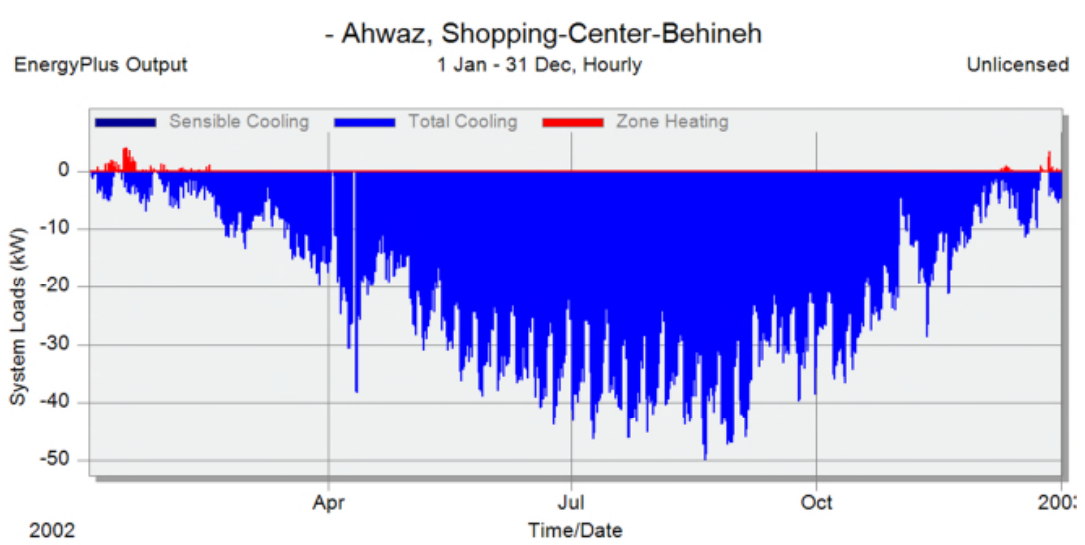


Figure 10- Hourly results of cooling and heating loads of building

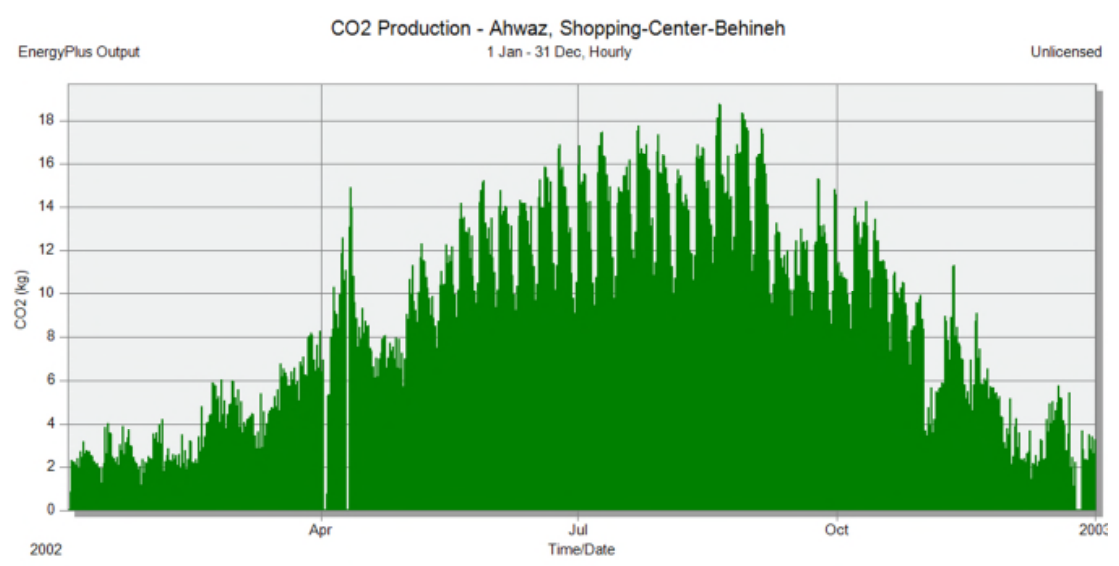

Figure 11- The hourly results of $\mathrm{CO} 2$ production

\section{1-Modelling solar cooling system}

As it was said, the solar system design is based on auxiliary systems. The designed solar model consists of production circuits (solar collectors, axillary cooling and heating), transfer circuits (storage reservoir, absorptive chiller and cooling system) and productivity (heating, cooling and hot water). This section is simulated using Pistache software. The solar cooling system is designed with solar 50\% and the applied absorptive chiller is SAKURA SHL with capacity $20 \mathrm{~kW}$ and efficiency coefficient 0.72 .

In this paper, to select the applied module among the Iranian products, LG250S1C-G2 model from LG factory with nominal power $250 \mathrm{w}$ is used in zero energy building. This module is made of monocrystalline silicon (mono-Si) with the area of $1.593 \mathrm{~m} 2$ with 60 cells. The efficiency of this solar plane is $15.71 \%$. To select the size of system with consumed load information as hourly and System Advisor Model, an array with 78 modules is designed to produce nominal power $20 \mathrm{kw}$ at standard efficiency period. A good angle declination for modules is $30^{\circ}$. Although we can install required equipment on modules to follow sun in one or two regions to achieve the maximum efficiency, due to the expensive and complexity of these equipment, the support of plane is constant. For this array, an inverter $18 \mathrm{kw}$ is used to convert direct electricity to alternative current with efficiency $95 \%$. Totally, $124 \mathrm{~m}^{2}$ of planes is used to generate electricity. This area of planes covers the majority of roof and yard of building.

Figure 12 illustrates net output energy for each system in a month. This chart is in full consistency with horizontal radiation chart. According to this model, the systems show the lowest radiation and energy production in December, January and February. 
Bulletin de la Société Royale des Sciences de Liège, Vol. 86, special edition, 2017, p. 372 - 387

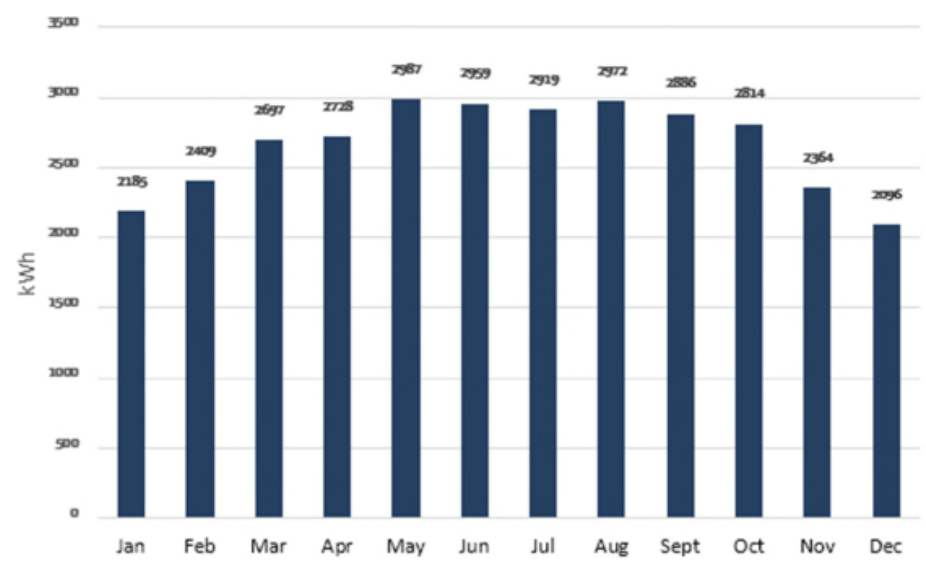

Figure 12- The monthly net output energy

Figure 13 shows the efficiency of modules in each hour in the first year. The efficiency of modules is reduced with the temperature increase and it is increased with the temperature decrease.

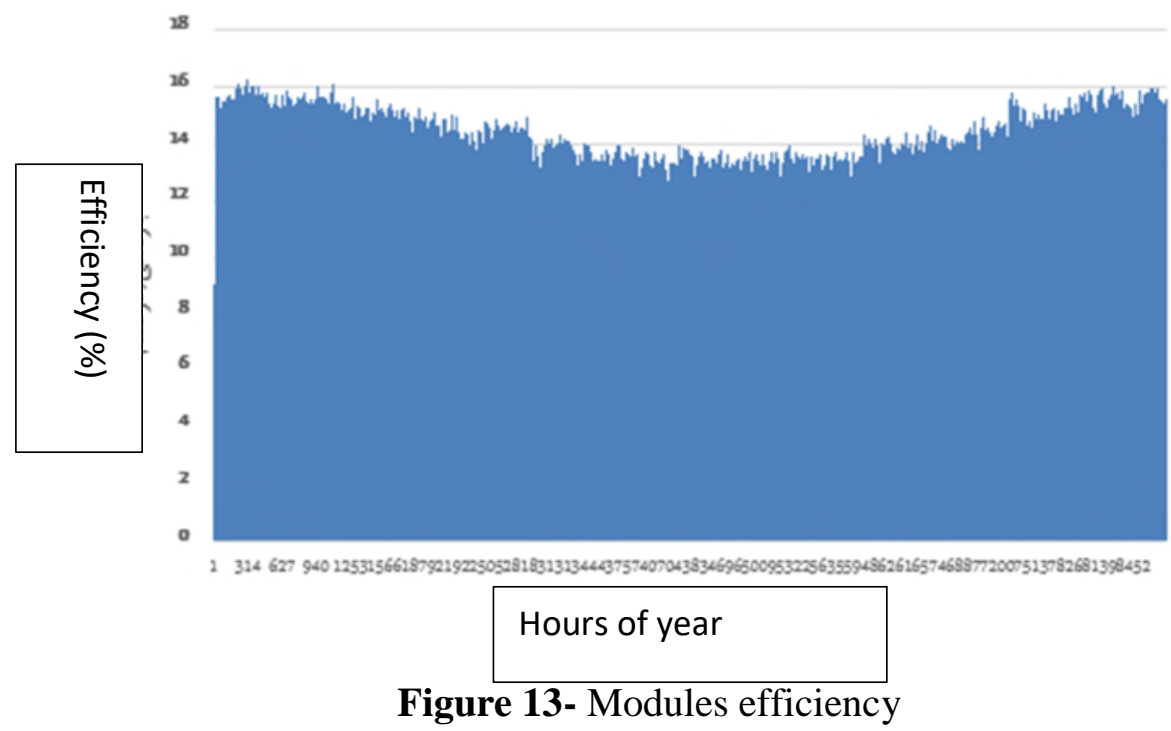

Regarding simulation of design of building from technical aspects, the summary of results of energy consumption and production are shown in Figure 14. This Table shows additional consumption of heating and cooling systems as pumps and fan of HRV. In this Table, $\mathrm{E}_{\text {aux }}$, $E_{\text {auxsol }}$ are total electricity consumption of cooling systems and total electricity consumption of solar systems. As shown in the Figure, total energy in solar systems and total energy in cooling systems is $7595,11939 \mathrm{kw} / \mathrm{h}$, respectively. 


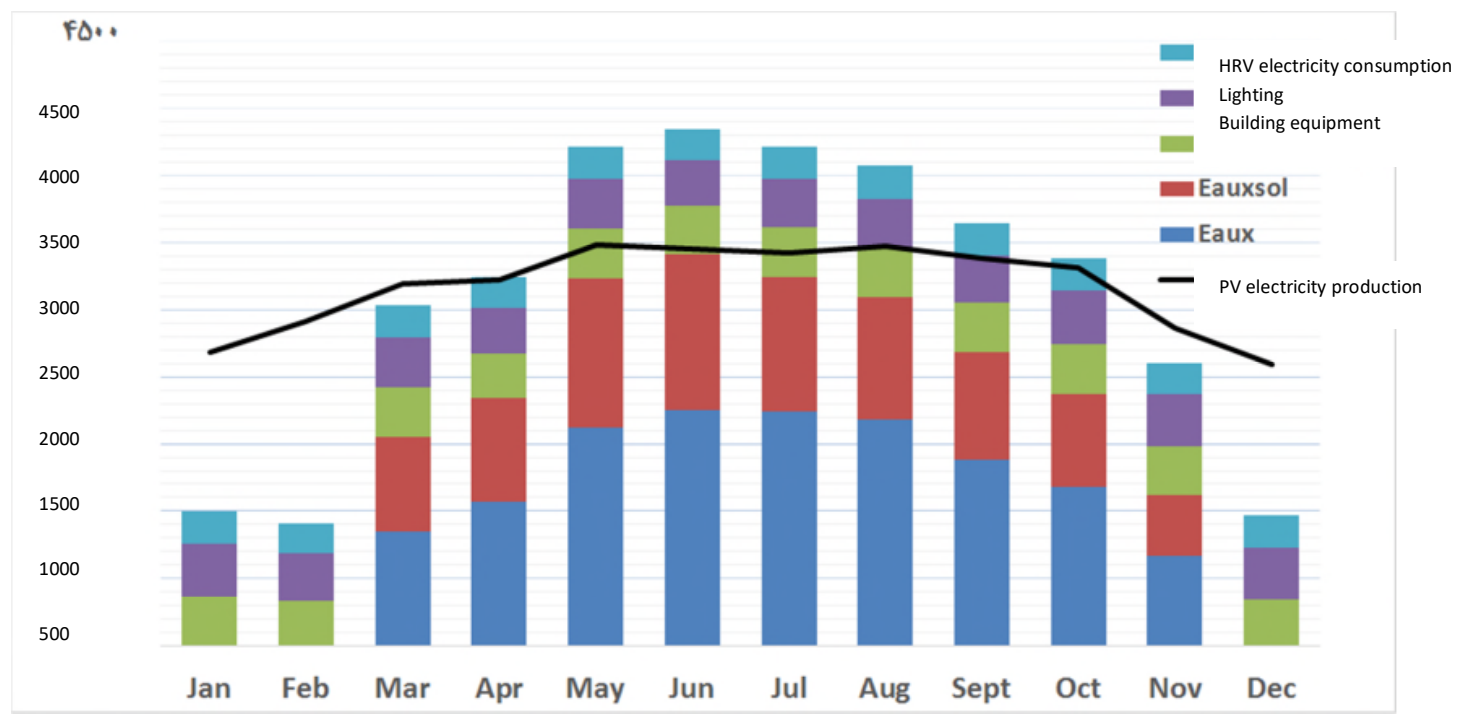

Figure 14- The summary of results of energy consumption and production in building

\section{Reliability assessment}

As the design of a zero energy building in Ahvaz city is based on its connection to the power grid, the load supply problems are reduced and the building can be in connection with the grid. In May, June, July, August, September and October, the need to electricity was higher than the generated power by photovoltaic panels and the building could supply the rest of energy via the global grid. In January, February, March, April, November and December with the lower need of electricity of building than the electricity produced by photovoltaic panels, the building could sell this extra power to the grid.

\section{3-Conclusion}

Using solar energy in the design of zero energy building reduces energy consumption. The best technical design was extracted using AutoCAD software and analytic software of Design builder. To select the size of system, System Advisor model (Sam) software was applied. The software model of solar cooling system was simulated using PISTACHE software. The shell features of building play important role in heating and cooling loads. Reduction of heating and cooling loads and maintaining the comfort of residents (here, thermostat temperature for cooling and heating is $25,20^{\circ} \mathrm{C}$ ) can reduce the size of heat and cold air equipment. Using maximum natural lighting, ventilation recycle system, using high efficiency windows, shade, high efficient electric equipment, etc. can reduce energy consumption considerably in building as total index of consumption (cooling, heating, gas and electric equipment, hot water and lighting) can reach suitable level.

\section{References}

[1] Deputy of electricity and energy. 2015. Tehran. Energy balance of 2015. 
[2] Bedir, A., B. Ozpineci, and J. E. Christian. "The impact of plug-in hybrid electric vehicle interaction with energy storage and solar panels on the grid for a zero energy house." IEEE PES T\&D 2010. IEEE, 2010.

[3] Serag-Eldin, M. A. "Thermal design of a modern, two floor, zero energy house in a desert compound." Thermal Issues in Emerging Technologies Theory and Applications (ThETA), 2010 3rd International Conference on. IEEE, 2010.

[4] Missoum, M., A. Hamidat, K. Imessad, S. Bensalem, and A. Khoudja. "Impact of a gridconnected PV system application in a bioclimatic house toward the zero energy status in the north of Algeria." Energy and Buildings128 (2016): 370-383.

[5] Kwan, Yuanming, and Lisa Guan. "Design a Zero Energy House in Brisbane, Australia." Procedia Engineering 121 (2015): 604-611.

[6] Lindberg, Karen Byskov, David Fischer, Gerard Doorman, Magnus Korpås, and Igor Sartori. "Cost-optimal energy system design in Zero Energy Buildings with resulting grid impact: A case study of a German multi-family house." Energy and Buildings (2016).

[7] Shafie, Maryam et al., 2013. Good form of building to receive radiation energy in Tehran. Tehran University.

[8] Zhang, S., Zhuang, Z., Hu, Y., Yang, B., \& Tan, H. (2016). Applicability Study on a Hybrid Renewable Energy System for Net-Zero Energy House in Shanghai. Energy Procedia, 88, 768-774.

[9] Rodriguez-Ubinas, E., Rodriguez, S., Voss, K., \& Todorovic, M. S. (2014). Energy efficiency evaluation of zero energy houses. Energy and Buildings, 83, 23-35.

[10] http:// www. Iranwether.ir

[11] Quej, V. H., Almorox, J., Ibrakhimov, M., \& Saito, L. (2016). Empirical models for estimating daily global solar radiation in Yucatán Peninsula, Mexico. Energy Conversion and Management, 110, 448-456. 